This report was prepared as an account of work sponsored by the United States Government. Neither the United States nor the United States Atomic Energy Commission, nor any of their employees, nor any of their contractors, subcontractors, or their employees, makes any warranty, express or implied, or assumes any legal liability or responsibility for the accuracy, completeness or usefulness of any information, apparatus, product or process disclosed, or represents that its use would not infringe privately owned rights.

In the interest of prompt distribution, this LAMS report was not edited by thi Technical Iniormation staff.

Printed in the United States of America. Available from

National Technical Information Service

U. S. Department of Commerce

5285 Port Royal Road

Springfield, Virginia 22151

Price: Printed Copy $\$ 3.00$. Microfiche $\$ 0.95$ 


\author{
LA-5019-MS \\ An Informal Report \\ UC. 20 \\ ISSUED: August 1972
}

\title{
The Low-Density Limit of the Theta Pinch
}

by

Michael Kaufmann*

*Max-Planck-Institur Fur Plasmaphysik, 8046 Garching. Bai Munchen, Germany.

NOTICE

This report was prepared as an account of work sponsored by the United Stutes Government. Neither the United States nor the United States Atomic Energy Commistion, nor any of their employees, nor any of their contractors, subcontractors, or their employees, makes any warranty, express or implied, or assumes any logal linbility or responsibility for the accuracy, com. pieteness or uxfulness of eny information, apperatus. product or prociss disclosed, in represenis that its use would not infinge privately owined rights. 
THE LOW-DENSITY LIMIT OF THE THETA PINCH

by

Michael Kaufmann

ABSTRACT

In the following, the scaling of the onset of sheath broadening in $\theta$-pinch implosions is derived on the basis of a number of assumptions. The most realistic is that the fnstability threshold is that of the electron-cyclotron-drift instability and that the electrons are heated by resistive or diffusive fleld mixing during the implosion. This scaling is used to order various existing high-voltage $\theta$-pinch experiments and to predict the conditions for excessive broadening of the sheath in future $\theta$ pinches and other shock-heating experiments.

\section{INTRODUCTION}

The theta pinch is a successful device for producing a high ion-temperature plasma. ${ }^{1-5}$ The ion heating is usually well described by the snowplow or similar models with additional adiabatic heating. 5 According to these models and experimental results the ion temperature rises roughly proportional to the Inverse filling density. But with decreasing filling density a linit of this dependence was found experimentally. 3-5 Below this 1imit the Ion temperacure is lower than the scaling law predicts, and at the same time diffusion during the first compression weakens the effect of the driving fieli. The compressed plasma has $\beta$-values below 1 which become smaller with decreasing filling density . ${ }^{6}$ It turned out that the sheath broadening in this region cannot be explained by Spitzer's resistivity. 5,7

The enhanced diffusion during the first compression of a theta pinch has hitherto not been satIsfactorily explained. Simple estimates show drift velocities in the sheath much less than the electron thermal velocity, and twi-stream instabllities are therefore excluded. $^{8}$ Ion acoustic waves have a much lower instability limt at the ion sound velocity and were regarded as responsible for the diffusion. But the essential condition for unstable Ion acoustic waves that $T_{e}$ be much larger than $T_{1}$ is violated
In a high energy theta pinch, even during the first compression. 8 Unstable Berustein waves have a critical velocity ${ }^{9}$ which is low enough to be reached by the drift veisnt $\pm y$ in the sheath of a theta pinch, and so in all probability these instabilities are exclted in the Iinear range.

Recent results of computer simulation studies presented a new situation. $15,16,23,24$ The mechanIsm in the nonlinear range seems to be different from the mechanism of the linear theory. In this completely new situation on the theoretical side the Instability limit is unknown. Computer experiments hitherto cover only a parameter range with a drift velocity near the thermal velocity of the electrons. Besides this, in the computer experiments the starting point of the nonlinear instability is usually not treated in an appropriate way. A lower number of particles in a Debye cell in the computer studies compared with experiments produces too much thermal noise.

Future simulation studies should yield a limit of fast growing nonlinear instabllitles, depending on the drift velocity in relation to other characteristic velocities of the plasma. The object of this paper is to get some idea of this critical drift velocity by analyzing existing experimental results. Such an empirical result should meanwhile 
relp us in different ways. The information may serve as a comparison with future simulation studies. it the moment it can be used for planning experiments and predicting the limit of good compression in a theta pinch. The empirical derivation of the dependence of such a limit can also initiate new experiments to prove a speciel cependence.

The possibility of empirically deriving a scaling law for the limtt of a good compression is based on relatively new experiments. Older experiments $1,5,19$ were carrled out in a narrow range of parameters. Compression experiments with increased tube radius and much higher voltages ${ }^{10-12}$ extended this parameter range sufficlently to derlve new scaling laws. In the new experiments the density limt for good theta pinch compression was reduced by three orders of magnitude compared with the slder exper 1 ments and correspondingly high ion temperatures were rached. 12

For the proposed derivation of scaling laws different assumptions about an instability limit of the drift velocity in the sheath will be made in the following. Together with other simplifying assumptions scaling laws showing the dependence of the critical filling density from other initial parameters of the pinch will be derived and compared with experimental results.

A. Derivation of the Ciftical Density Under Different Assumptions About the Diffusion Mechantsm

1. Fundamental Assumptions. Different instability limits rere assumed to be the major cause of the diffusion of the magnetic field during the first compression of a theta pinch. In order to derive simple scaling laws, it was assumed that instabilities in the unstable range always grow fast enough. This means that the instabilities should increase the electron temperature and decrease the drift velocity so fast that the parameters are always near the instability limit. For simplification it was therefore assumed that Inside the sheath the parameters fust satisfy the marginal limit of the instability which is considered. The way in which the instabilities grow in the unstable range, especially the nonlinear behavior, is not considered here.

Assuming such an instability limit to be fust fulfilled inside the sheath gives a relation between the magnetic field fump, density, and electron temperature inside the sheath. To get another relation between these quantities, an assumption about the ratlo between the magnetic fleld energy and the dissipated energy in the sheath is made. The derfvation of this ratio under not very stringent condtions is given in the Appendix.

It is assumed that the energy dissipated is gained by the electrons. It is further assumed that the magnetic field outside the plasma rises Inearly with time. To determine an averaged magnetic field during compression, the time of the snowplow model was taken to give the time for the first compression. Even, if one assumes a model in whth the lons are elastically reflected at the magnetic field jump, the compression time will not be essentially changed. The critical inftial density $n_{c, e}$ is defined as the initial density at which the thickness of the sheati about half-way through the first compression becomes half as thick as tube radius. It was shown experimel.tally in agreement with bounce model calculations ${ }^{5}$ that at about this point the ion heating starts to become inefficient and to lag behind the snowplow or similar models assuming a sharp boundary of the plasma. Ionization during compression is not taken into account. At low filling densities, when no lonization takes place during compression, the density of the ionized part of the gas should be taken as the intial density $n_{0}{ }^{10-12}$ At high densities nearly all neutrals are lonized during compression, and so the filling density shcald be taken as an initial density. The fonization energy can be included in the energy balance of the sheath, but this is not done here.

Altogether four different cases, assuring four different dominant limits of the diffusion process, will be considered in the following. It is assumed that unstable Bernstein waves, lon-acoustic waves $\left(T_{e}>T_{1}\right)$ or two-stream instabilitefes $\left(T_{e} \propto T_{1}\right)$ are responsible for limiting the drift velocity. Furthermore, Spitzer's resistivity is assumed to determine the diffusion. In Table 1 the different assumptions are compiled. 
TABLE 1. SLMMARY OF ASSUMPIIONS USED TO DETERMINE SHEATH DIFFUSION PROCESSES.

D

(1) $v_{D}=v_{t h} \frac{(1) c_{,} e}{11 p_{0} e} \quad v_{D}=c_{s} \quad v_{D}=v_{t h} \quad \eta=n_{\text {Spitzer }}$

$$
E_{t h}=E_{\text {mag }}
$$

$$
t_{c}=\left(\frac{r_{t}}{B_{0}}\right)^{1 / 2}\left(m_{0} m_{i} n_{0}\right)^{1 / 4}
$$

$$
n_{0, c}: \Delta_{r}=\frac{r_{t}}{2}
$$

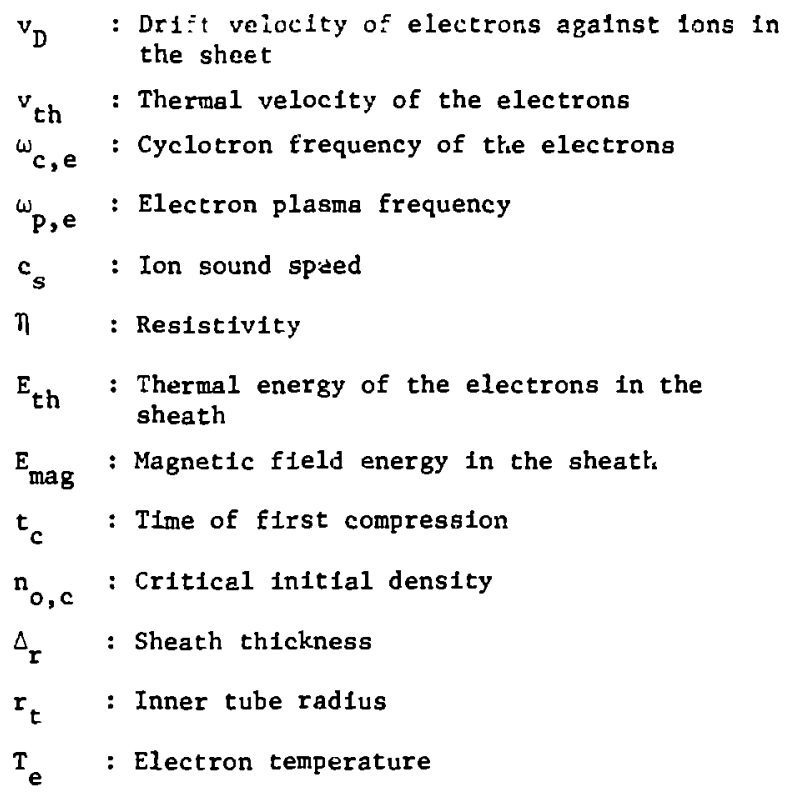

II. PHYSICAL QUANTITIES OF THE SHEATH

In Fig. 1 the assumed simplified profiles for the magnetic field $B$, density $n_{e}$ and temperature $T_{e}$ are shown as a function of $r$ for the case where $\Delta_{r}=\frac{r_{t}}{2}$ just half-way through compression. $B_{1}$ is assumed to be equal to $t \cdot \dot{B}_{0}$ and $B_{1} \gg B_{1,0^{\circ}}$

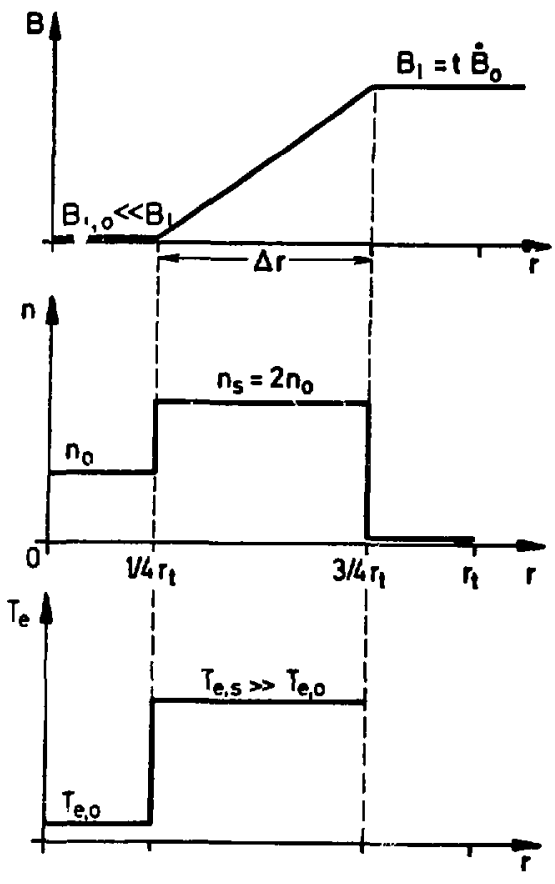

Fig. I according to the assumed linear drop of $B$ inside the sheath the irift velocity is

$$
v_{D} \propto \frac{B_{1}}{A_{r} n_{s}} \quad n_{s}=2 n_{0}
$$

Fig. 1. Diagram of the sheath parameters. 


$$
v_{D}\left[\frac{\mathrm{cm}}{\mathrm{s}}\right]=2.5 \cdot 10^{5} \frac{\mathrm{B}_{2}[\mathrm{kG}]}{\Delta_{r}[\mathrm{~cm}]_{0}\left[10^{16} \mathrm{~cm}^{-3}\right]}
$$

The tharmal velocity of the electrons in the sheath 18

$$
v_{t h}\left[\frac{\mathrm{cm}}{\mathrm{s}}\right]=2.3 \cdot 10^{9} \sqrt{\mathrm{T}_{\mathrm{e}}[\mathrm{keV}]} .
$$

The electron cyclotron frequency averaged over the sheath is

$$
\omega_{c, e}\left[8^{-1}\right]=8.8 \cdot 10^{9} B_{1}[k G] .
$$

\section{Plasma frequency}

$$
\begin{aligned}
& \omega_{\left.p, e^{\left[s^{-1}\right.}\right]}=5.6 \cdot 10^{12} \sqrt{n_{s}\left[10^{16} \mathrm{~cm}^{-3}\right]} \\
& \text { w } p, e^{\left[\mathrm{s}^{-1}\right]}=\mathrm{B} \cdot 10^{12 \sqrt{\mathrm{n}_{\mathrm{o}}\left[10^{16} \mathrm{~cm}^{-3}\right]}} \text {. }
\end{aligned}
$$

Ion sound speed:

$$
c_{s}=\sqrt{\frac{2 k_{m}^{m} e}{m_{1}}},
$$

whirh in the case of deuterium is:

$$
c_{s}\left[\frac{\mathrm{cm}}{\mathrm{s}}\right]=3.1 \cdot 10^{7} \sqrt{\mathrm{T}_{\mathrm{e}}[\mathrm{kev}]} \text {. }
$$

The magnetic energy inside the sheath 18

$$
E_{\text {mag }}=\frac{1}{2 \mu_{0}}{\overline{B^{2}}}^{s}=\frac{i}{6 \mu_{0}} B_{1}^{2}
$$

III. CRITICAI, DENSITIES UNDER DIFFERENT ASSIMMTIONS

\section{Case A}

Assuming the drift velocity to be limited by

$$
v_{D}=v_{t h} \frac{w_{c, e}}{w_{p, e}} \text {. }
$$

the sheach thickness turns out to be

$$
\Delta_{r}[\mathrm{~cm}]=\frac{10^{-1}}{\sqrt{n_{0}\left[10^{16} \mathrm{~cm}^{-3}\right] \mathrm{T} e^{[\mathrm{keV}]}}} \text {. }
$$

The energy relation gives (L) :

$\mathrm{B}_{1}^{2}[\mathrm{kG}]=3.6 \cdot 10^{3} \mathrm{n}_{\mathrm{o}}\left[10^{16} \mathrm{~cm}^{-3}\right] \mathrm{T} e^{[\mathrm{keV}](2 \mathrm{~A})}$

and together with $(1 \lambda)$ :

$$
A_{r}[\mathrm{~cm}]=\frac{6}{B_{1}[\mathrm{kG}]} \text {. }
$$

It should be noted that this result is very close to the assumption

$$
\begin{aligned}
& \Delta_{r}={\frac{c}{w_{r, e}}}^{+1} . \\
& \Delta_{r}[\mathrm{~cm}]=\frac{1.7}{B_{1}\lceil k G]} \text {. }
\end{aligned}
$$

Actually, in this case one gets

Assuming that the compression tim: $t_{c}$ is given by the time scale of the snowplow ${ }^{13}$

$$
t_{c} \approx{\frac{r_{t}}{B_{0}}}^{1 / 2}\left(\mu_{0} m_{i} n_{0}\right)^{i / 4},
$$

a typical $B_{1}$ during compression is taken to be

$$
B_{1}=B\left(\frac{t_{c}}{2}\right)=\dot{B}_{o} \frac{t_{c}}{2} \text {. }
$$

Th1s gfves a sheath thickness for deucertum of

$A_{r}[\mathrm{cni}]=\frac{15}{r_{t}[\mathrm{~cm}]^{1 / 2} B_{\mathrm{B}}\left[\frac{\mathrm{kg}}{\mu \mathrm{s}}\right]^{1 / 2} \mathrm{n}_{0}\left[10^{16} \mathrm{~cm}^{-3}\right]^{1 / 4}}$.

If one sets $\Delta_{r}=\frac{r_{t}}{2}$

as a limit, one bets as a critical lower der ity limit

$$
n_{0, c}\left[10^{16} \mathrm{~cm}^{-3}\right]=\frac{0.8 \cdot 10^{6}}{r_{t}[\mathrm{~cm}]^{6} B_{0}\left[\frac{\mathrm{kg}}{\mu \mathrm{s}}\right]^{2}}
$$

Expressed in terms of $u_{t}$, the Induced voltage around the inner surface of the tube (vacuum case),

(A) $n_{0, c^{15}}\left[10^{16} \mathrm{~cm}^{-3}\right]=\frac{0.8 \cdot 10^{3}}{r_{t}[\mathrm{~cm}]^{2} \mathrm{U}_{t}^{2}[\mathrm{kV}]}$.

Th1s result w111 be compared with experimental results later. First however, dertvations of critical densities under other assumptions w111 be given.

\section{Case B}

Now the drift velocity is assumed to be ilmited by

$$
\begin{aligned}
& v_{D}=c_{s}=\sqrt{\frac{2 k T_{e}}{m_{i}}} \\
& v_{D} r \frac{\Delta m_{s}}{s}=3.1 \cdot 10^{7} ?_{\mathrm{T}_{e}[\mathrm{keV}]}
\end{aligned}
$$

Together wit', the expression for the drift velocity, the energy relation (2) and the definition of the critical density (4) one gets: T) The general dependence of $\Delta r$ from the rat fo $\frac{v_{D}}{v_{t h}}$
is dertived by Chodura. 
( $\mathrm{E}:$

$$
\because 0 . c^{10} 10^{16} \mathrm{~m}^{-3}=\frac{1}{r_{t} \mathrm{~cm}^{2}}
$$

It shall be pointed out that it is possible to get essentially the same result by assuming the sheatt thickress to be of the order of

$\frac{c}{1 " p i}:$

$\left(1 \mathrm{~B}^{\prime}\right.$

$$
\Lambda_{r}=\frac{c}{n_{p i}}
$$

Together with relation (4) this yields:

$$
\mathrm{n}_{0, c}\left[10^{16} \mathrm{~cm}^{-3}\right]=\frac{0.4}{r_{t}[\mathrm{~cm}]^{2}}
$$

\section{Cise C}

In an aralogous way the assumed linit

$$
v_{D}=v_{t h}
$$

gives a criti:al density a factor $\frac{2}{3} \frac{m_{e}}{m_{i}}$ lower than
case B

$$
\text { (c) } n_{0, c}\left\lceil 10^{16} \mathrm{~cm}^{-3}\right\rceil=\frac{1.75 \cdot 10^{-4}}{r_{t}\lceil\mathrm{~cm}\rceil^{2}} \text {. }
$$

\section{Case D}

Finally, the case with only classical diffusion is treated. Neglecting any dynamics and assuming a constant resistivity in the sheath the diffusion is described by:

$$
\frac{\lambda^{2} B_{2}}{\lambda r^{2}}=\frac{\mu_{0}}{n} \dot{B}(r)
$$

For simplification it is assumed that

$$
\begin{aligned}
& \frac{\Delta B_{z}}{(\Delta r)^{2}}=\frac{\mu_{0}}{n} \dot{B}(r) \\
& \Delta B_{z}=\frac{1}{2} t_{c} \dot{B}_{o} \\
& \bar{B}(x)=\frac{1}{2} \dot{B}_{0}
\end{aligned}
$$

Spitzer's resistivity is: ${ }^{14}$

$$
{ }_{s}[\Omega m\rceil=4 \frac{10^{-8}}{T_{e}\left\lceil\mathrm{keV}^{3 / 2}\right.} \quad(\ln \lambda=12, z=1)
$$

which gives:

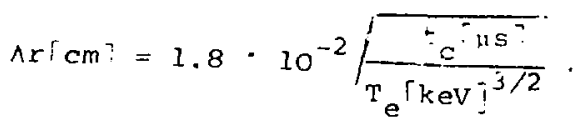

Together with relations (2), (3), and (4) one finally gets:

$$
\begin{aligned}
& \text { (D) } \mathrm{n}_{0 . \mathrm{c}}\left[0^{15} \mathrm{~cm}^{-3} ?\right. \\
& =3 \cdot 10^{-4} \mathrm{~B}_{\mathrm{o}}\left[\frac{\mathrm{kg}}{\mathrm{vg}}\right\rceil^{2} \mathrm{r}_{\mathrm{t}}[\mathrm{cm}]^{3} \\
& =0.3 \mathrm{u}_{\mathrm{t}}{ }^{2}[\mathrm{kv}\rceil \mathrm{r}_{\mathrm{t}}^{-1}[\mathrm{~cm}\rceil .
\end{aligned}
$$

In contrast with cases $A, B$, and $C$, this critical density represents an upper limit of the density. In nearly all experiments the filling densty is well below this limit. This means that classical Iffusion is not mainly responsible for the observed strong sheath broadening.

IV. COMPARISON WITH EXPERIMENTAL RESULTS

The density limit $n_{o, c}$ of cases $A, B$, and $C$ are now compared with experimental results.

F1gure 2a shows a comparison of experimental results with case A-the assumption of a drift velocity limit near $\frac{w_{\text {ce }}}{w_{p, e}}$. v $v_{t h, e^{*}}$

Experiments number 1 to 4 are older $\theta$-pinch experiments $3-6,19$ carried out at Los Alamos and Garching. By reducing the filling density it was clearly shown in these experiments that the lon heating deviated from snowplow scaling, and that diffuston of the magnetic field occurred at the same time. The density range where this deviation takes place is indicated as the experimental result for the critical density.

Experiment 5 has been proposed to be carried out with the Scyllac bank. The scaling law of the critical density snould be found by varying the hank voltage up to a fact.rr of three. In the experiments 6 and $7^{11}, 12$ the critical density was not systematically varied. Sut under these exper:mental conditions the sheath thickness was comparable with the tube radius, which means that relation (4), the defintion of the critical density, was just satisfied. As further proof the 1.or 


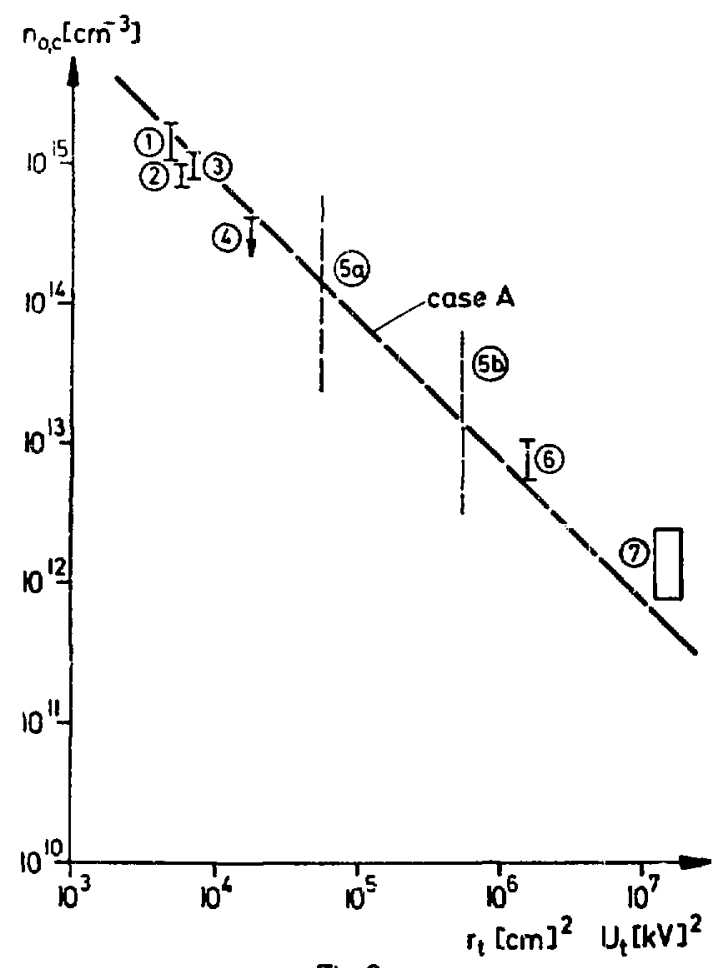

Fig. $2 a$

- $\mathrm{Ig}$. 2a. Critical density, comparison of experimental results with case $A$.

(1) Isar $\mathrm{IV}^{5}$

(2) Isar I, $1.5 \mathrm{~m} \mathrm{coil} 1^{4}$

(3) Scylla IV $\mathrm{V}^{3}, 25,26$

(4) Isar $I, 5.4 \mathrm{~m} \operatorname{col} 1^{19}$

(5) Scyllac, proposed experiment

(a) $\mathrm{U}_{\mathrm{t}}=40 \mathrm{kV}$

(b) $\mathrm{U}_{\mathrm{t}}=120 \mathrm{kV}$

(6) Jülich shock experiment 11

(7) Maryland shock experiment 12

r.eating of these experiments was compared with the snowplow model and relatively good agreement was found as well.

All experimental results are quite close to the estimated curve $A$ and also show the same relative dependence $r_{t}{ }^{2} \cdot u_{t}{ }^{2}$ and the same absolute value.

The comparison of the experimental results with case B (Fig. 2 b) show less good agreement. The experimental values of $n_{o, c}$ do not seem to scale

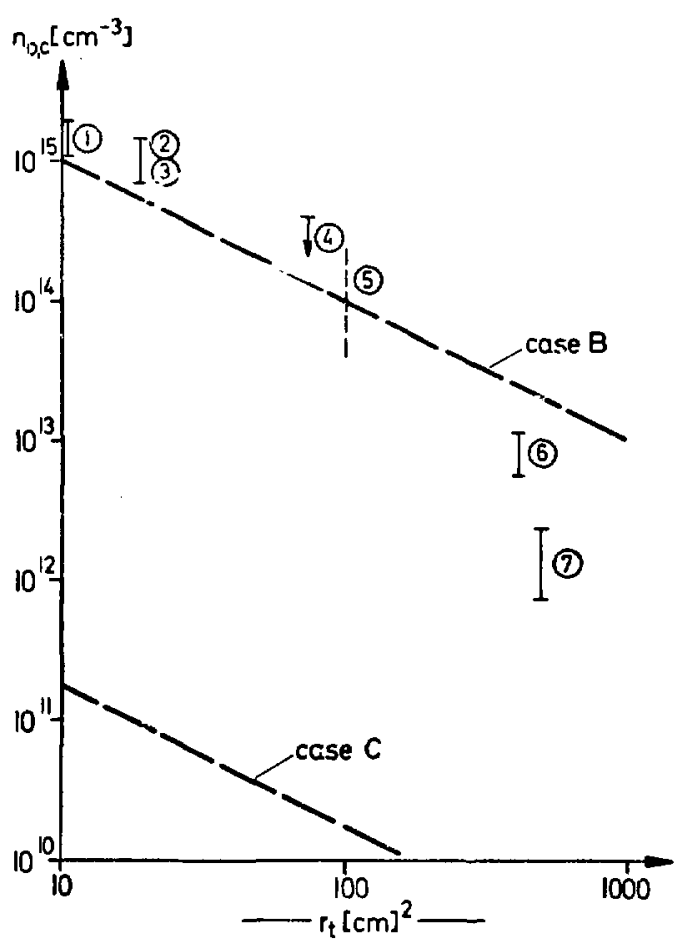

Fig. 2b

Fig. 2b. Critical density, comparison with cases $B$ and $C$.

with $\mathbf{r}_{t}^{2}$, which means that the sheath thickness does not scale as $\frac{\mathrm{c}}{\text { "'pi }}$.

Case $C$ deviates from the experimental results by more than three orders of magnitude. This clear1y shows that the plasma is unstable, even if the drift velocity is much less than the thermal electron velocity. This result is in contrast with onedimensional simulation results ${ }^{17}, 18$ showing the drift velocity and the thermal electron velocity close together in the nonlinear range. Summarizing, we can state that the existing experimental results concerning the critical density fit best with the assumption of a limit for the drift velocity near the onset of the electron cyclotron instability, which leads to a dependence of $n_{o, c} \sim U_{t} r_{t}{ }^{2}$. But it must be pointed out that more experiments are necessary to prove this dependence conclustvely.

V. SOME FINAL REMARKS 
$\therefore$ Some special points have to be observed in analysirg experimental results to get the critical density. Reference has already been made to the influence of the ionization energy, which was not taken into account in the preceding estimates. Up to $70 \mathrm{eV}$ can be needed for one ionization process. 20 Krowing the degree of preionization and assuming complete ionization during compression, one can compare the ionization energy with the thermal energy of the electrons according to relation (2). If the ionization energy is an appreclable part of it, the electron energy is lowered and the diffusion of the magnetic field instde the sheath is increased.

Another effect which could give misleading results is sheath broadening after the first compressfon especially if one determines the ion energy at the time of maximum adiabatic compression and compares it with a model for the ion heating, a strong reduction compared with this model need not be a sign of strong diffusion during the first compression only. Short circuiting of the electric field In the boundary sheath of the plasma over the ends 21,22 leads to sheath broadening and a reduction of the ion temperature 21 .

A more technical point is the fact that the voltage around the coll may have a rise time comparable with the compression time. In this case $v_{t}$ in the above estimates has to be a value averaged over compression. The experimental results of Fig. 1 include corrections for this effect as far as it is known.

B. The relations for the critical density derived above only show a dependence on the initial voltage and tube radius. In every case the gas was assumed to be deuterium. Regarding only the most interesting cases $A$ and $B$ a different scaling with the ion mass $m_{i}$ was found. The ion mass enters the estimates of $n_{0, c}$ by relation (A3) and(B1). Similarly to the preceding derivations, one gets:

$$
\begin{array}{ll}
\text { Case is: } & n_{0, c} \sim \frac{1}{m_{i}} \\
\text { Case B: } & n_{0, c} \sim m_{i}
\end{array}
$$

itis different scaling of the critical density with the ion mass should be used for an experimental investigation. A change from deuterium to hydrogen gives a relative varlation of the critical densities in both cases by a factor of 4. Experiments with Argon and Xenon at Julichll do not show the dependence of Case $B$.

c. It is posstble to derive a ratio of the electron temperature $T_{e}$ inside the sheath to the ion temperatule $?_{i_{1}}$ after the first compression trom assumptions (2) and (3). This ratio does not depend on any of the pinch parameters $r_{t},{ }^{r}, n_{0}$ and $m_{i}$. There is also no dependence on the diffusion mechanism (relation (1)). Taking the same factors to average over the sheath as above, one gets an estimate of the electron temperature of the sheath from relation (2):

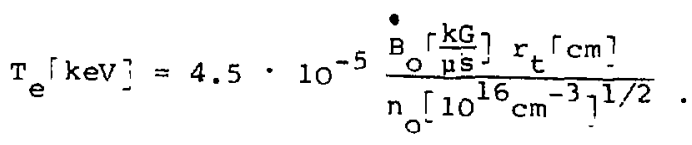

setting the ion velocity after the first compression:

$$
v_{i} \approx \frac{r_{t}}{t_{c}}
$$

and the fon temperature:

$$
k \mathrm{~T}_{\mathrm{i}_{\mathrm{L}}}=\frac{1}{2} \mathrm{~m}_{\mathrm{i}} \mathrm{v}^{2}
$$

one gets:

$$
T_{i \perp}\lceil\mathrm{kev}\rceil=1.6 \cdot 10^{-3} \frac{\dot{B}_{0}\left[\frac{k G}{\mu s}\right] r_{t}[\mathrm{~cm}]}{n_{0}\left[10^{16} \mathrm{~cm}^{-3}\right]^{1 / 2}} .
$$

This yields a ratio:

$$
\frac{\mathrm{T}_{\mathrm{e}}}{\mathrm{T}_{\mathrm{i}_{1}}} \approx \frac{1}{30}
$$

Experiments carried out in the collision-free range $3,4,6$ show rations between $\frac{1}{10}$ and $\frac{1}{20}$. Bearing In mind the number of simplifications, this is a reasonable agreement.

\section{ACKNOWLEDGMENTS}

The author would like to thank Dr. R. Chodura, Dr. B. M. Marder, Dr. R. L. Morse, Dr. J. Neuhauser, Dr. F. L. Ribe, Dr. R. E. Stemon, and Dr. H. Weitzner for fruttul discussions and $R$. Wunderlich for computer calculations.

REFERENCES

1. D. E. Nagle, W. E. Quinn, W. B. Riesenfeld and W. Leland, Phys. Rev, Lett. 3, 318 (1959). 
․ L. M. Guldmann, R. W. Kilb and H. C. Pollack, Phys. Fluids I, 1005 (1964).

3. E. M. Little, W. F. Quinn and G. A. Sawyer, Phys. Fluids $\underline{8}, 1168$, (1965).

4. C. Andelfinger, G. Decker, E. Funfer, A. Heiss, M. Keilhacker, J. Sommer and $M$. Elrich, in "Plasma Physics and Controlled Nuclear Fusion Research" (International Atomic Energy Agency, Cu1hatr, England, 1965) Vo1. 1 pp.249-260.

5. R. Wilhelm, Z. Physik 222, 208 (1969) and IPPReport 1/87 (1968).

6. M. Kautmann, J. Neuhauser and H. Rohr, IPPReport 1/105 (1970).

7. H. A. B. Bodin, J. McCartan, A. A. Newton and G. H. Wolf, Proceedings Conference Plasma Physics Controlled Nuclear Fusion Research, Novosibirsk, $\mathrm{CN}-24 / \mathrm{K}-1$, (1968).

8. U. Schumacher, Z. Physik 227, 162 (1969) and IPP-Report i/93 (1968).

9. D. W. Forslund, R. L, Morse and C. W. Nielson, Phys. Rev. Letters 25, p. 1266, (November, 1970)

10. M. Kellhacker, M. Kornherr, H. Niedermeyer, K. H. Steuer and R. Chodura, in "Plasma Physics and Controlled Nuclear Fusion Research" (International Atomic Energy Agency, Vienna, 1971), Vol. III, p. 265.

11. P. Bogen, K. S. Dietz, K. H. Dippel, E. Hintz, K. Hothker, F. Siemsen and G. Zeyer, in "Plasma Physics and Controlled Nuclear Fusion Research" (International Atomic Energy Agency, Vienna, 1971), Vol. III, p. 277.

12. W. D. Davis, A. W. De Silva, W. F. Dore, H. R. Griem, N. A. Krall and F. C. Liewer, in "Plasma Physics and Controlled Nuclear Fusion Research" (International Atomic Energy Agency, Vienna, 1971), Vol. III, p. 289.

13. S. Glasstone and R. H. Lovberg, Controlled Thermonuclear Reactions, Princeton, (1960).

14. I. Spitzer Jr., Physics of Fully Ionized Gases, New York, (1967).

15. D. Fors..und, R. Morse and C. Nielson, in "Plasma Physics and Controlled Nuclear Fusion Research" (Internat:Ional Atomic Energy Agency, Vienna, 1971), Vol. II, p. 277.

16. D. Blskamp and R. Chodura, in "Plasma Physics and Controlled Nuclear Fusion Research" (International Atomic Erergy Agency, Vienna, 1971), Vol. II.,P. 265.

17. R. L. Morse and C. W. Nielson, Phys. Rev. Letters, 26, 3, (1971).

18. D. Biskamp and R. Chodura, IPP-Report $6 / 97$.
19. E. Funfer, M. Kaufmann, W. Lotz, J. Neuhauser, M. Munich and U. SeldeI, IPP-Report uncer preparation.

20. R. W: P. McWhirter and A. G. Hearn, Proc. Phys. Soc. $82,641,(1963)$.

21. R. L. Morse, Phys. Fluids, 10, p. 1560, (1967).

22. M. Kaufmann, E. Funfer, J. Junker, J. Neuhauser and U. Seide1, IPP-Report 1/123, (1971).

23. D. W. Forsiund, R. L. Morse and C. W. Nielson, Phys. Rev, Lett. 27, 1425, (1971).

24. M. Lampe, W. M. Mauheimer, J, H. Drens, R. Shanny and R. N. Sudan, Phys. Rev, Lett. 26, 1221 (1971).

25. F. C. Jahoda, E. M. Little, W. E. Quinn, E. L. Ribe and G. A. Sawyer, J. Appl. Phys. 35,2351, (1964).

26. R. F. Gribble, E. M. Little, R. L, Morse and W. E. Quirın, Phys. Fluids, 11, 1221, (1968).

27. R. Chodura, Phys. Fluids, 11, 400, (1968).

\section{APPENDIX}

It is assumed that outside a conductor with a plane surface and constant resistivity $(\eta=$ const. if $x>0, \pi=0$ if $x \leq 0$ ) a homogeneous magnetic field rises with constant $\dot{B}$. The magnetic field is parallel to the surface $\left(\vec{B}(t)=\left(0,0, \dot{B}_{0} \cdot t\right)\right.$, $x<0, t \geq 0)$. At the beginning the magnetic field is zero everywhere $(\vec{B}(t=0) \equiv 0)$. $\mathrm{B}_{z}$ inside the conductor follows the equation:

$$
\dot{\mathrm{B}}_{\mathrm{z}}=\mathrm{D} \frac{\partial^{23_{z}}}{\partial \mathrm{x}^{2}} \quad \text { with } \mathrm{D}=\frac{\eta}{\mu_{0}} .
$$

The subgtitition

$$
B_{z}(x, t)=\dot{B}_{0} t f(\xi) \quad \xi=\frac{x^{2}}{D t}
$$

leads to

$$
4 \xi E^{\prime \prime}+\left(2+F_{3}\right) E^{\prime}-E=0 \quad \xi \geq 0
$$

with the boundary conditions:

$$
f(0)=I \text { and } \lim _{\xi \rightarrow \infty} E(\xi)=0 \text {. }
$$

The solution is:

$$
f(F)=A(2+F) \int_{\xi}^{\infty} \frac{1}{(2+s)^{2}} \frac{e^{-\frac{s}{4}}}{s^{1 / 2}} d s
$$


Calculating now the magnetic energy $E_{\text {mag }}$ and the dissipated energy $E_{d i s}$ inside the conductor, one finds: $\quad E_{\mathrm{mag}}=\frac{1}{2 \mu_{0}} \mathrm{~B}_{\mathrm{z}}{ }^{2} \mathrm{dx}$

$$
\begin{aligned}
& \left.=\frac{\dot{B}_{0}^{2} t^{2}}{2 \mu_{0}}: f(x, t)\right]^{2} d x \\
& =\frac{1}{4 \mu_{0}} I_{1} \dot{B}_{0}^{2} D^{1 / 2} t^{5 / 2}
\end{aligned}
$$

with $\quad I_{:}=\int_{0}^{\infty} q^{-1 / 2} \mathrm{f}^{2}(E) \mathrm{dg} \approx 0.64 \mathrm{~A}^{2}$

$$
\begin{aligned}
& E_{\text {dis }}=\frac{D}{\mu_{0}} \int_{0}^{t} \int_{0}^{\infty}\left(\frac{\lambda B z}{\lambda x}\right)^{2} d x d \tau \\
& =\frac{4 \dot{B}_{0}^{2}}{\mu_{0}{ }^{D}} \int_{0}^{R} x_{0}^{2} x^{\prime} \Gamma(x, t) \eta^{2} d x d \tau \\
& \text { with }=\frac{4}{5 \mu_{0}} I_{2} \dot{B}_{\circ}^{2} D^{1 / 2} t^{5 / 2} \\
& I_{2}=\int_{0}^{\infty} e^{1 / 2} f^{\prime}(p)^{2} d p \sim 0.25 A^{2} .
\end{aligned}
$$

As a time independent ratio of both energies one gets:

$$
\frac{E_{\text {dig }}}{E_{\text {mag }}}=1.25
$$

